Conhecimento TRADicional

\section{Legislação ainda não garante a repartição dos benefícios}

A Fazenda Chapada está localizada em Barra do Corda ou "Terra dos Índios", uma pequena cidade a 350 quilômetros de São Luiz, no Maranhão. $\mathrm{Na}$ Chapada a colheita não é de frutos, as folhas é que recebem todos os cuidados. A árvore de jaborandi (Pilocarpus spp.) detém a pilocarpina, princípio ativo de uma das drogas mais usadas em oftalmologia, cuja patente foi registrada em 1991 pela Merck, multinacional alemã do ramo farmacêutico. A entrada do jaborandi na lista de espécies ameaçadas de extinção, a mecanização da colheita em larga escala pela empresa, e a possível substituição pela pilocarpina sintética enfatiza a importância do debate sobre o uso do conhecimento tradicional versus os benefícios das comunidades detentoras. Para Fernanda Kaingang, advogada e diretora executiva e financeira do Instituto Indígena Brasileiro para Propriedade Intelectual (Inbrapi), o Estado precisa ser mais atuante no empoderamento das comunidades tradicionais.

"A questão do acesso a esses saberes tradicionais é problemática, mas náo é a principal. O fundamental é saber se os benefícios dessa apro- priação estáo sendo repartidos com a comunidade", afirma Fernanda. Quando a Merck chegou à região, no final da década de 1960, comprava as folhas de jaborandi colhidas pela população local. Entretanto, "desde o início estava claro para a empresa que o estoque natural de folhas de Pilocarpus poderia acabar", conta Claudio Urbano Pinheiro, pesquisador do Departamento de Oceanografia e Limnologia, da Universidade Federal do Maranhão (UFMA). "Eles concluíram que a única solução seria a domesticação do recurso natural, um processo que avançou com a aquisição, em 1989, de 2.250 hectares de uma propriedade rural no município de Barra do Corda”, explica. No sistema extrativista de retirada das folhas de jaborandi, os coletores entram nas matas durante a estação seca (julho a dezembro). Eles afirmam que as plantas toleram esse procedimento e que novas folhas rebrotam depois da colheita, quando do início da estação chuvosa. Entretanto, segundo Pinheiro, a coleta excessiva e frequente de folhas da mesma planta ou grupo de plantas resultou em danos ecológicos para as populaçóes naturais de jaborandi, "com redução ou mesmo desaparecimento das árvores em muitas partes do estado do Maranhão", afirma o pesquisador. Desde 1992, o jaborandi está na Lista Oficial de Espécies da Flora Brasileira Ameaçadas de Extinção, publicada pelo Instituto Brasileiro do Meio Ambiente e dos Recursos Naturais Renováveis (Ibama).

"A relação entre a companhia farmacêutica e as comunidades que foram levadas à coleta de folhas de jaborandi não parece ter sido uma relação bilateral em termos de benefícios diretos", acredita Pinheiro. Para ele, o benefício pecuniário resultante da coleta e venda de folhas foi temporário (enquanto duraram as populaçôes naturais da planta). Não houve melhorias socioeconômicas relevantes e duradouras trazidas pela exploração para as comunidades envolvidas. Mesmo na área de influência da fazenda da Merck, não aconteceram melhorias sociais diretas como, por exemplo, a geração de um número expressivo de empregos. "A expectativa de emprego foi maior apenas no início da implantação da plantação, a qual se tornou, mais tarde, quase totalmente mecanizada, dispensando grande parte da necessidade da máo de obra local”, completa.

REPARTINDO BENEFÍcIOS No aspecto legal, o acesso ao conhecimento tradicional é permitido e, muitas vezes, estimulado. A Convenção sobre Diversidade Biológica (CDB), um dos principais resultados da Conferência das Naçóes Unidas para o Meio Ambiente e o Desenvolvimento (CNUMAD, ou Rio 92), realizada no Rio de Janeiro, em junho de 1992, ratificado pelo Brasil em 1994, tem três 


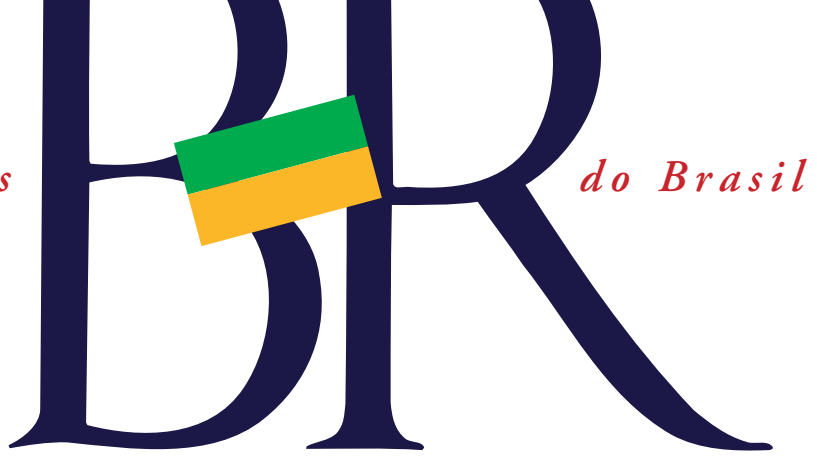

objetivos: a conservação da diversidade biológica, o uso sustentável de seus componentes e a repartição justa e equitativa dos benefícios resultantes do uso dos recursos genéticos, conforme explica Fernanda, do Inbrapi. Portanto, já existe um respaldo legal para proteção do conhecimento tradicional, ainda que disperso em vários instrumentos. Além disso, também aumentou a participação dos povos indígenas e das comunidades tradicionais nas discussôes para elaboraçấo e aperfeiçoamento dessa legislaçáo. "Como acontece no Brasil, de forma geral, a legislação não é conhecida pelos próprios beneficiários. Isso é ainda mais grave com relação aos povos indígenas porque são populaçóes de tradição oral, com altos índices de analfabetismo. Eles têm mais dificuldade de compreender um ordenamento jurídico complexo e segmentado e de colocar isso em prática", acredita a advogada.

De acordo com Claudio Pinheiro, hoje pouco pode ser feito para as comunidades envolvidas. "Se a Merck tivesse tido interesse poderia ter estimulado pe- quenos plantios de jaborandi, fornecendo os insumos, assistência e garantindo a compra das folhas", diz. Porém, a plantação em grande escala torna essa prática pouco interessante para a empresa. Além disso, o pesquisador da UFMA afirma que a Merck já considera substituir a produçáo de pilocarpina natural pela sintética. "Como consequência, certamente, restaráo apenas os danos ecológicos irreversíveis, com a destruição das populações naturais de Pilocarpus no Maranhão e o mau exemplo do uso exaustivo desse recurso vegetal, sua privatização e fi-

\section{JABORANDI NÃO É ENDÊMICA DO BRASIL}

O conhecimento de que as folhas do jaborandi fazem aumentar a produção de suor e a salivação, pertence, há séculos, aos índios Tupi-Guarani, que batizaram a espécies de yaborã-di ou planta que faz babar. 0 conhecimento dos índios sobre as folhas dessa árvore de pequeno porte chamou a atenção de viajantes e naturalistas europeus que visitaram o Brasil ainda no século XIX. Eles levaram as folhas para serem estudadas no Velho Continente. As folhas são a única fonte natural da pilocarpina, substância

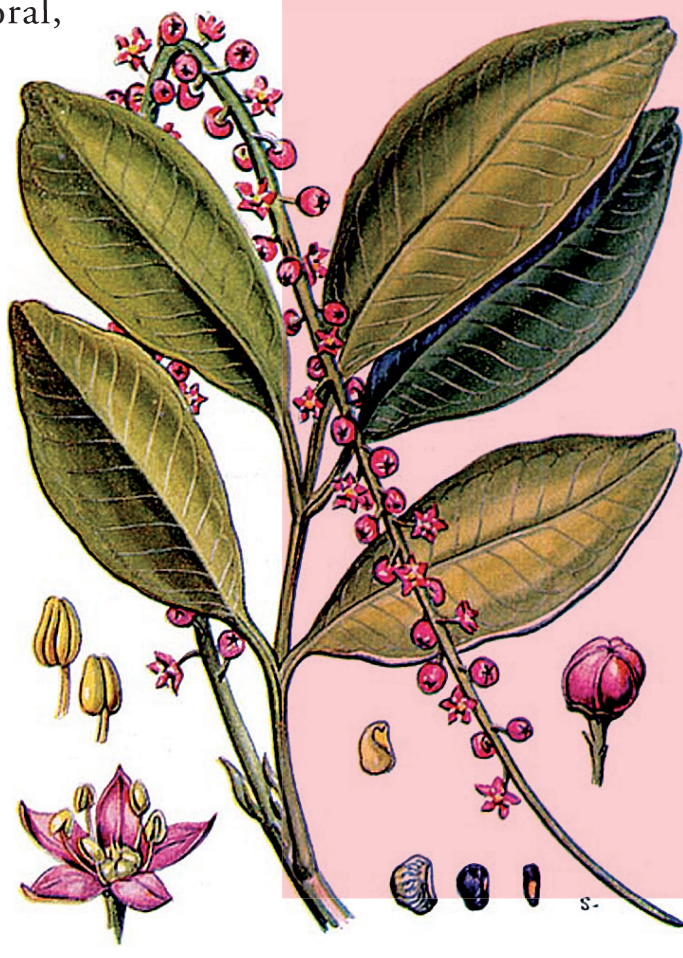
usada para contração da pupila, necessária em procedimentos cirúrgicos nos olhos. A substância é também usada no tratamento de glaucoma e para aliviar a sensação de boca seca em pacientes com câncer de cabeça e pescoço.

O jaborandi ocorre de norte a sul do Brasil, sendo que apenas no Maranhão são descritas três espécies, dentre elas a Pilocarpus microphyllus, detentora do maior nível de concentração de pilocarpina em suas folhas. Segundo Pinheiro, o jaborandi, se tornou, nas últimas três décadas, uma das espécies mais importantes da flora brasileira e o Maranhão o maior produtor de folhas de jaborandi do país.

Prancha XVIII: jaborandi de Dennis Jackson, The experimental pharmacology and materia medica, 1939 


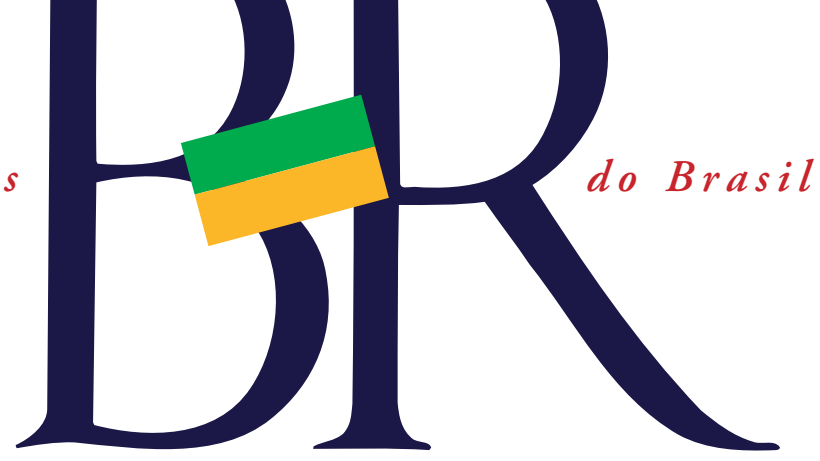

nalmente, seu abandono", conclui. Do ponto de vista legal, no entanto, Fernanda lembra que, mesmo no caso da produção da pilocarpina sintética, a comunidade teria direito de receber benefícios porque foi o seu conhecimento sobre a planta que originou o produto sintético. "O que acontece, na prática, é que o conhecimento tradicional não é valorado da mesma forma que o conhecimento científico. "No entanto, essa sabedoria tem um valor por si mesma e é um desperdício que sejam abandonadas as tentativas de acessar esse conhecimento para náo repartir os benefícios gerados por ele", lamenta Fernanda.

FONTE DE LUCRO, FONTE DA VIDA Visões diferentes sobre os recursos naturais estão na base de conflitos como este. Enquanto a Merck vê a biodiversidade como fonte de lucro, para as comunidades tradicionais ela é fonte da vida. "Considerando que existe um arcabouço de proteçáo jurídica, espera-se que esse arcabouço seja considerado um princípio na relação das empresas e do Estado com os povos indígenas e com as comunidades tradicionais", afirma Fernanda. "Áreas de elevada importância biológica são ocupadas por povos indígenas e por comunidades tradicionais. Se os países fossem calcular a compensação por serviços ambientais mantidos nessas áreas conservadas, esses povos teriam a receber. Quem mantém floresta em pé no mundo são as comuni- dades locais, eles são atores principais desse processo, mas quase nunca são considerados dessa forma em acordos, convenções etc", conclui.

A tendência do mercado de recursos genéticos, regulado por patentes e royalties, é valorar o conhecimento e não tanto o insumo, a biodiversidade. Sáo diversos os exemplos de medicamentos originados a partir do patrimônio genético brasileiro e boa parte dessas patentes são de empresas estrangeiras, já que a informação sobre a biodiversidade brasileira pode ser facilmente encontrada. "Quem precisa de instrumentos apropriados para conhecer e entender o valor do patrimônio genético são as comunidades locais e os povos indígenas. São eles que utilizam de forma sustentável e conservam os recursos naturais, por isso precisam de mais iniciativas de empoderamento, de formação de capacidades", defende a advogada.

Nesse sentido um Estado mais atuante é fundamental, seja local ou nacionalmente. "Precisamos de iniciativas de conscientização do Estado, das universidades e também do setor privado, para criar uma atmosfera, não de desconfiança, como percebemos hoje, mas que favoreça a proteção dos conhecimentos tradicionais e garanta a repartição justa dos benefícios gerados por ele", finaliza Fernanda Kaingang.

Patrícia Mariuzzo
AGRICULTURA FAMILIAR Faltam incentivos para
que a biotecnologia
germine no campo

A agricultura familiar é responsável por mais de $70 \%$ dos alimentos consumidos pela população brasileira. No entanto, apesar de representar $84,4 \%$ dos estabelecimentos agropecuários do país, segundo os dados mais atuais (Censo Agropecuário de 2006 - veja box), apenas os grandes latifundiários têm o capital necessário para o investimento em produtos biotecnológicos de ponta. Dessa forma, "ao passo que as grandes propriedades possuem cada vez mais subsídios do governo para o cultivo das principais commodities - como a cana-de-açúcar e a soja -, a agricultura familiar passa por dificuldades de ordem tanto técnica quanto política e econômica", destaca o engenheiro agrônomo Piero Oliveira da Embrapa Meio Ambiente. Muitos dos esforços feitos para estimular o avanço da agricultura no Brasil têm secundarizado a posição do chamado "pequeno agricultor" e valorizado o setor de biotecnologia, sobretudo a entrada de produtos em uma rede de importantes parceiros comerciais 